\title{
Behaviour and Literacy
}

Jack Goody

\section{Abstract:}

This article argues from a perspective that tries to transcend the historical, social, economical specificity of the notion of ,law'. As a more general term the term "jural behaviour" is suggested, especially for oral societies. On this basis, the author asks for the relation of literacy and law or jural behaviour respectively. As the comparative overview of historical and anthropological cases proves, literacy leads to extension of forms of behaviour geographically, it enables social mobility, it causes formalisation, and it leads to universalisation.

Jack R. Goody, fellow of the St. John's College and William Wyse Professor in Cambridge. Research on the history and anthropology of literacy, kinship, and flowers and food.

E-Mail: jrg1@cam.ac.uk
Keywords: behaviour; literacy; social anthropology

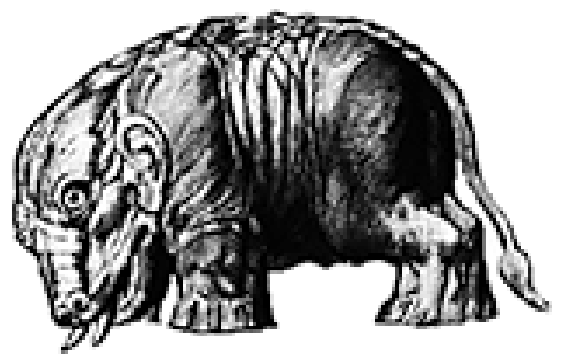


Let me begin by asserting that there is no society without jural behaviour. I use the term jural here as the equivalent of legal and the law in oral societies, where there is no court of law in our sense. The whole discussion about law is confusing unless we realise that lawful behaviour, action according to social norms, is just as prevalent before the emergence of writing and hence of law in a formal sense. Writing was important but formal behaviour, manners for example, existed long before. And no society is anarchic, without standards of behaviour, without jural norms.

If 'lawful behaviour', 'rules of right doing', exists both in purely oral and in literate societies, what does literacy do? Firstly, literacy expands the range of applicability for any specific rule because it replaces oral communication (which is essentially face-to-face) with communication at a distance through the written word. That means the range of application of norms is much more restricted without literacy which opens up the role of written behaviour guides to a much more extensive community. And that may invite hegemony and dominance as well as 'community'. Take China for example. When the Chinese state spread its tentacles to reach north Vietnam, an area which spoke quite a different language, at the same time it spread its Chinese writing to the conquered territories. Being non-phonetic that script could transcribe any language, so the characters were taught in schools (just as they are in Japan and Korea today). That meant that the Vietnamese could read Chinese guides to behaviour, such as how you should treat your father by showing 'filial piety'.

Consequently in China you had similar behaviour (and the same was true of funerals and marriages) spreading from the Manchus north of the country to the Thai south, irrespective of what had formerly been different norms in the constituent oral communities - a huge area, which is now a single market and one that has a common written language. So that the Chinese notion of a 'belief' in their ancestors, as well as the worship of the dead, was a norm of domestic behaviour, that continued to be widespread because of its formulation in Confucian texts. These written texts were instruments of colonial domination, much as English or French have been in Africa and elsewhere. They demand conformation with the dominant culture. But not only there.

Until very recently in a southern rural French newsagents I used to find a guide book to writing letters. Gone was the regional or dialectical variation (indeed you could be punished at school for not writing the langue d'oeil of northern France). Every letter was to begin with a certain phrase, depending on the rank of the person addressed, and had to finish in a certain way. Reçevez l'expression sincère de mes sentiments dévoué. That went for everyone, whatever the specific relationship as well as ironing out local differences. 
A further example is the quantity of the books purporting to act as guides to the Language of Flowers that appeared in Europe at the beginning of the nineteenth century. This was supposed by some of its adepts to have its origin in the secret language of the east; by others to hark back to the significance of flowers in country life, or in poetry, 'my love is like a red red rose'. In fact, though it might have been connected with both, it was an invented language in which each flower was given a specific meaning in a single list, so that you could use it to convey to your loved one a secret message, such as 'meet me in the park at twilight'. Again local differences disappeared. That listing made matters very different from the use in ordinary life where the red rose could stand not only for love, but for blood or even for the county of Lancashire, as in the Wars of the Roses that in England preceded the Tudor period. In other words, the significance depended not on a decontextualised list as in the guide book but very much on the context, whether it was love or battle, and very much on the region; a flower had different meanings in different parts. Whereas a text in writing ignored these differences, claimed to be universal and offer a single interpretation that covered all circumstances. Lists did this with other forms of behaviour. In this case, the so-called Language of Flowers was clearly linked to the purchase of cut-flowers from flower-sellers in the towns and to their reconstitution in bouquets where each component carried a single meaning. They made sense in a specific urban context, not as guides to specific rural usage, and they were inventions of a market-oriented society. Not that all such guides were like that but they had some element in common such as the instruction of the ignorant, or the socially mobile in a society where written education rather than oral society was dominant. Except that in this instance, you had an example of the 'invented tradition' discussed by the historian, Eric Hobsbawm, and others, not something that was a transcription of a custom in oral culture but as something 'created' in an urban economy. Law was rather similar.

What it is important to realise is something that our nineteenth (and indeed twentieth) century predecessors never did, that this shift to 'civility' - in the limited sense of the 'culture of cities', was not a purely European phenomenon. Karl Marx and many historians thought it was and Norbert Elias has even written of Europe as having developed 'civilization' at the Renaissance, based on the empirical examination of 'etiquette books' and similar manuals listing proper behaviour. But this was not the first of its kind, though their distribution was now greater because of the printing press. As I have pointed out, you get the same thing happening in China with Confucian texts on 'proper behaviour', for example to the father or to the whole category of relations in funeral ceremonies. The prescription of behaviour in a similar fashion is common to other literate societies, but it is also common in oral ones, 
too. When I lived among the LoDagaa of northern Ghana, everybody knew what kind of behaviour was appropriate not only to a father but to everybody else in the community. For example, if you had an uncle, a mother's brother who died, you had to bring a basket of grain to make beer. But it was more localized, less universal. It differed by settlement.

What differences did the advent of writing make to this kind of activity? I have argued that it made reciprocity much more precise. There would be some occasions in oral society where a man could not bring a basket. Now with writing his gift was being recorded, much as we sometimes do with Xmas cards. If you did not receive one in a certain year, you may not return one the next. Whereas in an oral society, you know that you should have brought your uncle a basket because that is what you do to uncles. Whether you did or did not may well have been forgotten whereas with writing one has a permanent reminder. This meant that the reciprocity of the gift took a different, more rigid form.

That seems to me the same in general with written guides to behaviour. These are not communicated face-to-face as in an oral society but exist as physical objects which are to be consulted in any circumstance and outside the context of action. They become more abstract, more generalised, more universal. For example, instead of saying 'Thou shalt not kill the French', one tends to find general exhortations to behaviour such as 'Thou shalt not kill'. That is not how human societies behave; they kill in some circumstance but not in others, they kill people with red hair but not those with black, depending on the circumstances. But in writing one tends to find general statements of the problem, so that gives rise to opposition groups of dissenters who take the word literally and refuse to take part in war at all. Because the written word, as in the Commandments, applies to the world at large, whereas in oral societies moral norms apply only to a limited, face-to-face, context, not to the wide expanse of a more universalistic, written religion that spreads over a wide area. The written guide thus becomes more generalized than the unwritten, less applicable to particular activities, more geared to the general and more universalistic, all men are brothers, but at the same time these injunctions are less applicable, more theoretical, less practised.

The conference in Vienna on "Behaviour Guides and Law" seemed to be concerned with the disparity between the formal law and the less formal (but still written) guides to action. To me the central difference has to do with the formalization of behavioural restrictions in a written code that is enforced by courts and constables and those unwritten codes that specify proper behaviour. The difference also lies in the sanctions that are applied to the censored behaviour, not only the sanctions but the context. In earlier times legal sanctions were not seen as applicable a) to many domestic disputes or b) to inter- 
national conflicts. In the former (until recently) the domestic family was meant to act internally; in the second, there was (until recently) no overarching tribunal (because no state) to intervene. Now there are some international bodies, including courts (though hardly adequate). Both these situations have partially changed. There is also a whole area of interpersonal relations in which transgression of the code is not seen as sufficiently important for legal sanctions to operate, instead informal sanctions come into play.

The growth of 'law' in this case has not impeded the growth of guidebooks to proper conduct. These proliferated, firstly with the coming of printing, much as with recipe books or books revealing the language of flowers. But that was not the most important factor. They certainly increased with the Italian Renaissance but to think that either they or the relevant behaviour began at that time, as Norbert Elias does in his well-known study, is to misunderstand the nature of human communication, specifically the effect of literacy worldwide. No doubt their importance increased in Europe at that time, when there was more movement between social groups so that the normal processes for the inculcation of 'refined' behaviour by domestic learning could not work; you learnt from books rather than in the family (by education rather than by socialisation). But behavioural guides not only generalize in space but also in time, i.e. when morals, customs, change, they remain the same, behind hand, relevant to an earlier age, as with the Jewish Levitical taboos and the Muslim (and Jewish) prohibition on pork. These are not necessarily written but if they are, they are more resistant to change and modification. It is the case that behaviour guides of this kind are especially valuable when the circumstances of peoples' lives are changing, as was the case with the growth of the bourgeoisie. With increasing pressure on social mobility you did not know what clothes to wear (dress according to rank as in sumptuary legislation had become less relevant), what food to serve, how to address those above us, all this required behaviour guides, not when the social structure is static, but when there was some movement. Also 'fashion' came to play a larger part in society as a whole; indeed, some circles marked themselves off by regular changes of fashion, as occurred in a formal way with the establishment of the court of Louis XIV and the silk factories of Lyon. To be 'in' you had not simply to be well-dressed in a traditional manner but to be so in a contemporary one that took account of increasingly regular changes (every six months).

However Europe was by no means the first to engage in fashion. Change always existed, even in socalled traditional societies and civilisations. But it was at a different rhythm, and was therefore less noticeable. It increased with the advent of writing and even more with that of the printing press, and 
now the computer; which has in a way replaced the guide book. One can consult the web to find the proper behaviour, the ads to see the proper dress.

Written guides to behaviour usually concern the less serious forms of action, recipe books, lists of the language of flowers, how to address a person, face-to-face or by letter, which often involved listing (to which I shall return below). Commandments as in the ten Christian ones (but elsewhere too) involve more serious restrictions or injunctions, 'love thy father and thy mother', forming a kind of behaviour guide and are sometimes incorporated in a legal code 'Thou shalt not steal'. What I have called 'less serious' are not always seen by the actors as such. Giving a Catholic wife chrysanthemums as a present breaks an important taboo, which does not exist in Protestant countries. These forms of behaviour are often stratified by class (eating peas with a fork, for example) or ethnicity (eating with only a fork, as in the States), whereas Commandments are religiously backed and therefore more serious (as with stealing or adultery).

Both may be 'listed'. Listing, I have argued, is a feature of written societies. Lists occur very frequently on the earliest clay tablets of Mesopotamia, where lists of trees, for example, were used to teach reading (and writing) in the schools that were established at that time. These lists took on a normative aspect. Behaviour guides were likewise a form of listing of proper actions, but the precepts are taken away from oral instruction and treated in a more abstract fashion. In other words with writing you are taking behaviour out of the context of particular social action and treating it in a more general way. It is the same with listing trees. I argue that in oral cultures there was virtually no occasion when you made a list of trees; you observed each one separately, if at all, in an actual context (so the general category was implicit). It was the same with guides or Commandments. You only produced a list of these in a decontextualized context, one involving writing.

Writing enables one to communicate with a wider, less personalized audience. A much larger number of people adopt the same written code, which eliminates or limits local diversity. Printing makes that even more widespread since it produces at one time a large number of similar copies (in manuscript cultures it is very different). All this means less local diversity and more uniformity.

Also the rules become more definite (fewer exceptions) when written down, more authoritative, more precise, for many people can look back to the same written text, less easy to avoid, especially when set within a religious context, as with the Commandments, which are not simply moral law but God's law. 
To sum up, guides to behaviour are not in principle new. In oral cultures, people learnt how to behave in the context of family or village life. There was little deliberate teaching, yet this did occur. In the Bagre society of the LoDagaa, whose myth I have recorded over 40 years, neophytes, those about to be made members (initiates), are deliberately told what belonging involves, like what food to eat and when, what objects to be used. There are sections in the Bagre which are specifically concerned with learning behaviour that only initiates know about. So what do behavioural guides, what does literacy do?

1. It spreads forms of behaviour over a wide area and a long time, especially if it is related to a religious doctrine e.g. the eating taboos in Exodus. Extension.

2. It not only generalizes in this sense, but it provides a mechanism for decontextualized learning, for reading about what you have to do by education as distinct from learning by socialization, by face-to-face. In this way it instructs people - in 'lower' groups (e.g. class) how to act if they want to be members of higher ones. Social mobility.

3. It appears to harden and to rigidify the behaviour of an oral kind that is, once written it is less easy to avoid. Formalization.

4. And this is perhaps an aspect of 1), it irons out the contextual differences to provide one norm for all. Universalization.

I have taken the whole question to be one of cultural evolution between societies with writing (and 'law-codes, courts and constables' as Bronisław Malinowski put it) and in purely oral societies. And while the informality of societies with writing is not the same as the practice of oral societies, there is some relationship. 